\title{
Home-to- School Connection: Literacy Practices of a Teenager Living in Tourist Area
}

\author{
${ }^{1}$ Faizatul Husna, ${ }^{2}$ Ida Muliawati, ${ }^{3}$ Surya Asra \\ ${ }^{1}$ STAIN Teungku Dirundeng Meulaboh, Indonesia, faizatulhusna88@gmail.com \\ ${ }^{2}$ Universitas Iskandar Muda, Banda Aceh, Indonesia, ida.thesyarils@ gmail.com \\ ${ }^{3}$ Universitas Samudra, Langsa, suryaasra2019@unsam.ac.id
}

Submitted: 22/04/2020 Revised: 12/05/2020 Accepted: 19/05/2020

How to cite this article: Home-to-school connection: Literacy practices of a teenager living in tourist area. IJELR: International Journal of Education, Language, and Religion, 2(1), 39-46.

https://doi.org/10.35308/ijelr.v2i1.2191

\begin{abstract}
The view of literacy as a social practice has changed the view of researchers to study not only the activities in formal setting but also beyond the school walls (Hull and Schultz, 2002; Street, 2003). This paper aims to shed light how foreign literacy practices in out-of-school context, particularly in tourist areas, may potentially contribute to the students' literacy ability in the formal context. This ethnographic research was conducted over a two-week period which situated in tourist destination areas, namely Gapang, in the municipality of Sabang, Indonesia. The input data comes mainly from participant observation, audio recordings, interviews and field notes to examine the linkages between outside literacy and school attainment. The findings suggest that there was a linkage between the literacy practices outside and inside school for participant. Eventually, this study will be a beneficial input for teachers, parents and researchers, in the future study, to take into account the learning experiences available in both settings and integrate them into fruitful literacy learning at school.
\end{abstract}

\section{Keywords}

Literacy practices; home and school; teenager; tourist area

\section{Introduction}

For many decades, literacy education commonly accepted that reading and writing skills are the technical skills of being literate, and that both of them must be taught in sequence order: writing is taught when reading is fully mastered (Heath, 1987). The theoretical framework of this traditional view of literacy is rooted in cognitive and psychological perspectives (Vygotsky, 1978), concentrating on the specific outcome of both skills. Therefore, early researchers interested in literacy studies took into account test results and, often, their frequency rates of reading and writing to see the overall achievement of the participants (Pearson et al, 1984).

As time has passed, the understanding of literacy has gradually changed, with a more expanding conception of literacy. People, apparently, no longer perceive literacy as an isolated skill of reading and writing, to further simply categorize it into the ambiguous definitions of literate, semiliterate or illiterate (Heath, 1987); now it is seen as the action taken to make sense of texts associated with social life. Moll et al (2001) highlight that a literate pupil is able to develop a new concept of language along with the inherited culture inside from the process of sense-making and interpretation of the texts. 
Kramsch (1995) inserts that the interpretation of author's intention is likely to be more successful done through negotiation and discussion with others. For the language learners, the author adds, the culture which is represented by a language may be well-learned through the socially embedded texts. This premise is in line with the understanding of literacy wherein it is regarded as a set of cultural practices in which the people engage (e.g. Barton \& Hamilton, 2000; Resnick, 2000). Therefore, it is suggested that the teaching of a foreign language, such as English, should consider several aspects from grammatical to cultural viewpoints.

Barton and Hamilton (2000) describe the literacy practices as the activities of reading and writing, which are embedded in social structures. From this idea, it is fair to say that it is not only schools which take on the responsibility of the of students' literacy development. Further, some authors (i.e. Kleeck, et al, 2003; Goodwyn, 2002; Dantas, 2010) applied the ethnographic method and came to the conclusion that parents and adults should also be involved in literacy practices outside the school context to help shape students' ability, beliefs and values. It is also interesting to draw on Hamilton's idea that the ethnography of literacy might be a useful resource in a curriculum for teaching a language in a formal context. Hamilton in Papen (2005) uncovers the potentiality and role of literacy's ethnography as a curriculum resource in language teaching, as it is also plausible to say that schools are not merely a source of literacy competence; they are somehow considered too isolated from texts in the context of everyday life. Yet, the practice of literacy must also take into account the social condition and context of a particular community; particularly how the community produces and uses texts in certain ways.

However, there are very few studies exploring students' literacy practices out of the school context, particularly in tourist areas in Indonesia, in which the English language might be important for various reasons. Following the ideas of Hudman \& Jackson (2003), the language and the development of tourist areas are tightly linked, since tourists will visit the countries that speak and develop their language. Apparently, to understand and to be understood is essential to influence tourism. In addition, many tourists will envisage the worst-case scenario, such as a health issue, while they are in a new place where no-one understands their language. This will inhibit them from even planning to visit said tourist destination.

Furthermore, from the social learning theoretical framework grounded in Vygotsky's notion (1978), it is largely accepted that the best way to learn a language is by continuous exposure to the target language. Thus the environment and community in which the students live are very influential in either hindering or promoting students' target language development.

Indonesia has several tourist destinations, one famous destination, among others, being Sabang (Kim \& Park, 2014). In some areas of Weh Island, literacy is practised in an informal space outside the school setting, as many teenagers help their parents work at shops, cafés, or at a diving centre; thus teenagers living around this area are unconsciously engaged into literacy activities. We assume that the many literacy events they encounter might contribute to their foreign language improvement; not only their literacy competence, but also their communication skills. Then, how the local and foreign languages available within the two sites and intersect each other in the multimodal texts with different types of tools and technologies was also interesting to see.

The term "literacy" has been understood in different ways by different people for many decades. Unsworth (1993) simply underlines this term as the written practices of particular texts that may vary, ranging from the study of religious texts to a simple reminder note, while a decade earlier Wagner et al (1984) expanded the notion of literacy into a more detailed explanation:

“... anything which involves one or more of the following: reading (from decoding individual letters to reading for comprehension); writing (from copying in allographic style on a luha to creative prose to numerical calculations on a scrap of paper in a local market); manipulation of written materials or books with the intent to use them for some purpose, or other activities in the material culture of literacy ..." (p.240). 
In recent years literacy is likely to have become an important element in English learning. In addition, it is no longer perceive as an isolated skill of reading and writing and classify it into the ambiguous definitions of literate, semiliterate or illiterate; now it is seen as the action taken to make sense of texts associated with social life. This premise is in line with the understanding of literacy wherein it is regarded as a set of cultural practices in which the people engage (Hamilton, 2000; Resnick, 2000). Therefore, it is suggested that the teaching of a foreign language, such as English, should consider several aspects from grammatical to cultural viewpoints.

Drawing from those notions, the researchers (Larson \& Marsh, 2014; Street, 2003) then categorize literacy into two distinct concepts, namely: the literacy event, which is grounded in Heath's 1983 theory, and literacy practice, established by Street in 1995, by which is meant all of the social practices which allow human interaction and interpretation. The first term, literacy event refers to the event in which the texts are used and discussed using particular language as a medium of communication through 'interpretations, extensions and meanings. Whereas the term literacy practices may be defined as the repetition of the events mentioned above. To better illustrate these two terms, Hornberger provides the instances of which they can be differed. Stories that parents usually read for their children before they go to bed can be an example of literacy event, meanwhile the repeated event of telling stories is classified as literacy practices (Hornberger, 2004; Parlindungan, 2017). Undeniably, the impact of technology has now shifted the way people choose the reading material not only from written text such as magazine, newspaper etc. As we are aware the resources are now available from various modes. People are able to communicate through written text, multimedia devices, mobile phone and photograph for which 'Second Life' is constructed and new identity is shaped (Walsh, 2010). The resources of materials available in informal settings can be a beneficial insight for teachers in integrating students experience and available knowledge with the material given in the classroom.

However, only few researchers have addressed the problem of multimodal literacies the students encounter inside and outside school particularly in tourist destination. The previous study from Nabhan and Hidayat (2018) investigating literacy practices in higher education level in Indonesian showed that there were limited sources of texts and digital material adopted in the classroom. In addition, there were the misconception emerged about English literacy skills in traditional view. The study from Wedin (2006) with the study case in primary school literacy education in rural Tanzania revealed the connection of literacy practices between rural region and school Tanzania. From his research it can be concluded that there is strong connection between language, literacy, and power.

\section{Method}

This ethnography study employs the qualitative method to describe the foreign language literacy practices of the teenager outside the school setting and to link it with formal school practices. In this research, we narrowed down the social context for two different sites: school and community, then literacy practices of English as a foreign language were analyzed, which is mainly experienced outside school in tourist area, and link it with classroom literacy practices.

The field work was conducted within a two-week period for both sites: the community and school settings. Observation in the classroom lasted a minimum of two hours for each visit, for the total of four days. I considered both sites in order to understand the actions of the participant's meaning-making in everyday practices, and to see the possible relationship between literacy activities outside and inside the school. The participant, which are the equivalent of high school age, was selected from local people. In gathering the data, mixed-methodological techniques were employed, namely participant observation, interview, audio-recording, field notes, and collection of documentary evidence such as maps, and brochures. 
In this study, Joni (17 years old) was chosen as the participant. He is able to speak in three different languages: English as a foreign language, Indonesian as a national and formal language, and Acehnese as the prominent indigenous language and lives in Gapang resort, which is not far from Iboih, the two well-known tourism spots in Sabang. Both of his parents passed away when he was very small. He was adopted by Dutch parents who own a diving center and resort business in that area. He is used to living with foreigners because his house, namely Dolphin Diving Center (pseudonym), is in a guesthouse complex. Joni uses English when communicating with his parents as well as with the guests. Although his parents use Dutch when communicating with each other, he felt reluctant to learn the language because it was quite complicated for him. Now, as he is majoring in multimedia at school, he is obliged to spend most of his time in front of the computer, designing websites, surfing the internet and spending his leisure time on Facebook. Indeed, his parents provide him with enough funds for his daily needs, such as for school and for his leisure activities, so that he neither needs to work nor to help his parents running their business. However, he asked his mother if he could fill the cashier position when their employees are off, every Wednesday after school hours.

Detailed observation, in this ethnographic approach, is regarded as the main activity in the data collection. Then, interviews and field notes during the collection of data become one package in the participant observation process. Yet sometimes, as literacy events occur spontaneously in ethnography studies, it is not always possible to record every single literacy event as it would interrupt the 'natural' communication between the informant and the community members. Thus, we kindly asked the participants to write a diary of some important literacy events he encountered within two different sites.

To analyze the data, the excerpts are taken from the interviews and talk recording transcriptions. They are analysed through the relevant theories of literacy practice across boundaries. Further, the collection of documentary evidence will be analyzed to see the differences between literacy practices occurring in school and out-of school, and the process of meaning-making from texts. The data in this study is described in words rather than numerically through the discourse analysis and observation of discursive practices to answer the following questions:

1. What are the differences between texts, tools and technologies used inside and outside school settings?

2. How the texts are produced and in what languages they are discussed within those particular sites?

3. What is the correlation between the informal foreign literacy experiences outside the school and students' participation in classroom literacy practices?

The excerpts are presented in this research using the pseudonyms of the participants and remain confidential. The Researcher is ' $\mathrm{R}$ '; participants are Joni (J) and teacher (T). Of equal importance, some researchers (e.g. Robson, 2011; Hammersley \& Atkinson, 2007; Gall, et al, 1996) explain that ethnography is a field study which is aimed at revealing and understanding the selected participants' experiences and their point of view about something. Accordingly, this fieldwork will depend largely on participant observation. For that reason, as the above researchers have suggested, it is deemed important to maintain a good relationship with the participants and the related parties by, for example, following ethical considerations in the research.

\section{Results and Discussion}

From the investigation of sources in reading and writing activities of Joni suggested that he encountered different texts they used in school and at home. At school, Joni read the isolated texts from particular textbooks. Meanwhile, he encountered a multimodal literacy activity outside the school, including comics, books, pictures and texts from digital technologies and sometimes with the involvement of numeracy literacy. Drawing from participant observation and interviews, it can be concluded that there was a connection between home and school practices for Joni. 
Joni was raised in a multilingual family from a very different background. His parents, who took custody of him when he was child, are from the Netherlands and used to speak Dutch. Joni did not understand his parents' language and had never made any attempt to learn it. His parents accept his language choice and they were comfortable enough to speak in English, rather than in Dutch or Indonesian. For Joni, an outgoing teenager, living in the guesthouse has allowed him to meet many people from different countries. He is, then, accustomed to such a living arrangement. At home, he loves to read some fiction books and comics. His passion for computer programs and software has driven him to enrol in vocational school, majoring in multimedia. It is not surprising, then, if he spent an equal amount of time engaged in activities utilizing the computer. He started learning to create a website and planned to make an advertisement for their diving business, which was previously only available in English. Utilizing digital technologies, he started the conversations via Facebook messenger with foreigners. During his leisure time, he would be stuck in front of his laptop on Facebook or designing a website. He would help running their business by serving the customers only every Wednesday when other workers are off.

Once, an interesting moment was captured at the guest house when he acted as a translator for both a tourist and a fruit seller from the local people In this extract, we see that his out-of-school literacy practices came mostly from exposure in his environment. Many literacy events happened incidentally, because his living environment allows him to meet many people and to encounter a distinctive practice. When he was working as a receptionist, he used recurrent vocabulary. For instance, when a guest asked for room prices, a map or to rent a motorcycle.

Apparently, Joni's recurrent activities at the guesthouse and home, have also been contributed by semiotic resources such as gesture. His interested in digital technologies, such as using the Facebook and creating website to produce texts, is aligned with his passion in multimedia at his school has transformed him as a multimedia literate.

At school, as his teacher revealed, Joni was an active student and his friends often asked him for help in the English lesson. Joni was always happy if his teacher asked him to read in front of the class with a loud voice. Therefore, we may assume that he has successfully constructed his identity as his friends have seen him as a competent English learner. He also joined in the debate team representing the school. His English teacher, David has been teaching in that vocational school for more than ten years

In one occasion, the English teacher asked the students to work in pairs. He selected the students himself and mixed them based on their ability. Joni was paired with his friend, Alfa. They were reading a map and used the relevant vocabulary. Below is the short extract from the lesson when David approached Joni and his peers working together to produce the text from the map.

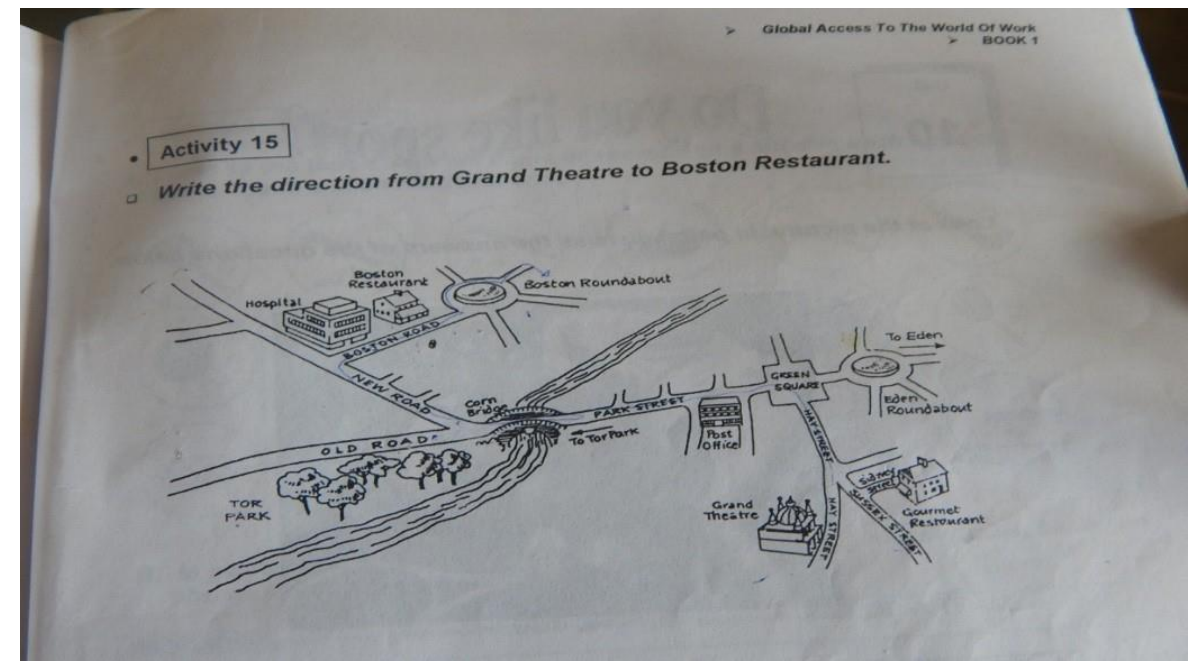

Figure 1: Map from the textbook 
The teacher provided some time for them to discuss the text and negotiate the meaning. Interestingly, all students were enthusiastically engaged in the text, including Joni and his partner. Then, the teacher provided the same type of task to be accomplished by them. He allowed his students to use whichever languages were convenient in the explanation of the text or asking questions, but the text that they should produce must be in English.

However, sometimes other students would like to ask Joni in the middle of a task, but he responded as quickly as possible because he was still doing his own task. In the middle of the task, the teacher walks around the classroom to make sure that his students are not stuck on a problem. Drawing from the observation data, I found that the teacher approached each group and was involved in conversation with them. Below is the conversation between Joni and Alfa with their teacher at their own desk:

\section{[JONI AND ALFA THEN DISCUSSED WHO WILL START THE CONVERSATION]}
139 A :
okay, Joni. Can you tell the way to the post office?
$140 \mathrm{~J} \quad$ :
sure, You just need to keep going this road, the Boston road,
141
then you will see the junction. You have to turn left to the Corn Bridge,
142
then cross it. Follow the Park Street, not really far from that
143 you will see the Post office on your right side. Ok!
144 A : Ok, thanks.
$145 \mathrm{~T}:$ good, now change your role.

The roles of the students above were shifted to give an opportunity for them to practise the texts as well as to develop their communicative competence. It was also noticeable that the teacher did not attempt to control nor interrupt the flow of their dialogues. Also, the flow was conducive to the discussion, since the ecology system which was evolved within the classroom seemed to be healthy; two students worked collaboratively and helped each other to become an expert. The teacher also implicitly pushed them to compete in a positive way. For example, he provided every partner with the same task from same map, but the direction assigned has been modified for each group. Thus, they did not feel that they have to use the exact same expressions as the other peers in order to be correct. Instead, within the time constraints, they would produce their own text with the appropriate sentences without cheating from the writings of other groups. In Joni's class, his teacher modified the task though it was explicitly from the same source text.

The text and map provided by his teacher were helpful in increasing his literacy ability through immediate practice in collaborative talks. For Joni, this text was quite familiar for him, since he commonly faced that kind of event at home. Hence Joni and his friend were able to accomplish the task much quicker than other students, further helping his peers after he was completely finished. In brief, he successfully transformed his identity as an expert in the literacy activities at school as he was also supported by his teacher, who provided an opportunity for his students to connect their own experiences beyond school with the literacy activities at school.

In addition, his passion to create texts using the computer was also supported by the department that he has chosen: multimedia. Thus, he can utilize technology such as computers, as is his passion, to create a website and to enhance his digital literacy at the same time. From the findings revealed, it is plausible to say that Joni has succeeded in the literacy practices situated in both social and formal contexts. His experience of literacy activities outside school at some point has had a huge impact on his attainment at school. This is also justified by his teacher's account of Joni's literacy activities at school and his attainment. For example, when his teacher asked them to work with peers in solving the map direction task, he has confidently showed his identity as a competent language learner. In the subsequent visit 
during lunchtime, the teacher welcomed me entering his room and talked about the things I needed to know. Of course, Joni's attainment at school attracted me the most. He exposed that:

"So far, Joni is doing well. He is an active student and his grades are also on the above average. I think his experience from his environment help him very much. But, haha (laughter), I don't even know that his parents are Dutch." Teacher of Joni.

From the teacher's account, it is revealed that Joni is not only smart, but he also provided support to his friends in the classroom in completing the task. Joni's identity has also been constructed as a competent learner, since his ability to manage his power in the classroom helped him to cope with the classroom ecology in both sites, at home and at school. In his classroom, the teacher's talking time was minimized, and allowed the students to interact with their friends or peers more frequently when negotiating the text. The teacher seemed to hold the weakest resolve for using L1 in the classroom, which postulates that the sparse the use of L1, the better (Cook, 2001). Leading on from this, it may be argued that the teacher wanted to improve the students' ability to express the text in English.

Joni's success in coping with the lesson at school was also supported by his ability to connect his knowledge which he gained from outside school practices at home and in the community. In addition, as Ornstein (1994) argued, that the reading material provided by his teacher was based on a real-life context has allowed him to reflect his own practices from home to school. Lastly, his teacher monitoring all students and moving around the class helps him and his classmates to be more confident in completing the task.

\section{Conclusion}

Reading and writing have been mentioned as the connective way for students to shape their fully structured language. The speaking and interaction that surround it will improve their language, since every student will make use of their language repertoire and cultivate their ideas based on their diverse experiences to further transform their skill into a more formal writing. It can thus be argued that sustained discussion and interaction by students with their fellows will foster their accomplishment in foreign language literacy with the acknowledgement of the psychological and sociological factors that underpin the construction of students' positive attitudes toward the text itself.

In Joni's case, his friends and community treated him as a competent writer and speaker in the literacy practices at school as he has successfully brought his experiences at home to the classroom. This match condition of literacy both out-of-school and within the school are greatly influenced by their ability to transform and bridge the diverse experiences they gained from both sites. The input data from the participant within an ethnographic framework then shed light on how teachers, parents and researchers, in the future study, must take into account the learning experiences available in both settings and integrate them into fruitful literacy learning at school. By the same token, this research encourages that society must acknowledge learners as active participants, particularly in out-of-school literacy activities.

\section{References}

Anne Van Kleeck, P. H., Van Kleeck, A., Stahl, S. A., \& Bauer, E. B. (Eds.). (2003). On reading books to children: Parents and teachers. Routledge.

Barton, D., Hamilton, M., \& Ivanic, R. (2000). Local literacies: Reading and writing in context. Psychology Press.

Cook, V. (2001). Using the first language in the classroom. Canadian Modern Language Review, $57(3), 402-423$. 
Dantas, M. L., \& Manyak, P. C. (Eds.). (2010). Home-school connections in a multicultural society: Learning from and with culturally and linguistically diverse families. Routledge.

Gall, M. D., Borg, W. R., \& Gall, J. P. (1996). Educational research: An introduction. Longman Publishing.

Goodwyn, A. (Ed.). (2002). Improving Literacy at KS2 and KS3. SAGE.

Hammersley, M., \& Atkinson, P. (2007). Ethnography: Principles in practice. Routledge.

Heath, S. (1987). Foreword. In H. Graff, Labyrinths of literacy (pp.vii-ix). New York: Cambridge University Press.

Hornberger, N. (2004). Continua of Biliteracy. An Ecological Framework for Educational Policy, Research, and Practice in Multilingual Settings, Language Problems and Language Planning, vol. 28, 2004. https://doi.org/10.1075/lplp.28.3.11car.

Hudman, L. E., \& Jackson, R. H. (2003). Geography of travel and tourism. Cengage Learning.

Hull, G. A., \& Schultz, K. (Eds.). (2002). School's out: Bridging out-of-school literacies with classroom practice (Vol. 60). Teachers College Press.

Kim, S., \& Park, E. (2014). First-time and repeat tourist destination image: the case of domestic tourists to Weh Island, Indonesia. Anatolia, (ahead-of-print), 1-13.

Kramsch, C. (Ed.). (2003). Language acquisition and language socialization: Ecological perspectives. Bloomsbury Publishing.

Kramsch, C. (1995). The cultural component of language teaching. Language, culture and curriculum, 8(2), 83-92.

Moll, L. C., Saez, R., \& Dworin, J. (2001). Exploring biliteracy: Two student case examples of writing as a social practice. The Elementary school journal, 435-449.

Nabhan,S., \& Hidayat, R. (2018) . Investigating Literacy Practices in a University EFL Context from Multiliteracies and Multimodal Perspective: A Case Study. Advances in Language and Literary Studies, Vol. 9, 192-199

Ornstein, A. C. (1994). The textbook-driven curriculum. Peabody Journal of Education, 69(3), 70-85.

Papen, U. (2005). Adult literacy as social practice: More than skills. Routledge.

Parlindungan, F. (2017). Literacy practices in a second language. TEFLIN Journal, 28(1), 115-132.

Pearson, P. D., Barr, R., \& Kamil, M. L. (1984). Handbook of reading research (Vol. 1). Psychology Press.

Resnick, L. B. (2000). Literacy in school and out. What counts as literacy: Challenging the school standard, 27-41.

Robson, C. (2011). Real World Research ( $3^{\text {rd }}$ Ed). West Sussex: John Wiley \& Sons

Street, B. (2003) Social Literacies: Critical Approaches to Literacy. London: Cambridge University Press.

Street, B. (2003). What's "new" in New Literacy Studies? Critical approaches to literacy in theory and practice. Current issues in comparative education, 5(2), 77-91.

Vygotsky, L. S. (1978). Mind in society. Cambridge, MA: Harvard University Press.

Wagner, D. A., Messick, B. M., \& Spratt, J. (1984). Studying literacy in Morocco.

Wedin, Åsa. (2006). Literacy Practices in Rural Tanzania: The Case of Karagwe. Journal of Multilingual and Multicultural Development. 27. 10.1080/01434630608668777. 